\title{
Luminescent Vesicles Self-assembled Directly from an Amphiphilic Europium Complex in an Ionic Liquid
}

\author{
Qingrun Li a , Shenghan Song ${ }^{b}$, Zhenyu Feng ${ }^{\text {a }}$, Juan Qiu a , Meng Sun ${ }^{\text {a }}$, Xiao Chen ${ }^{\text {a,* }}$ \\ ${ }^{a}$ Key Laboratory of Colloid and Interface Chemistry, Shandong University, Ministry of Education, \\ Jinan, 250100, China \\ ${ }^{\mathrm{b}}$ Department of Chemistry \& Chemical Biology, The University of New Mexico, Albuquerque, \\ New Mexico 87131, United States
}

This six-page SI material contains six figures and one table listed as following:

Figure S1. Size distribution of the aggregates formed by Tery-MEE@Eu $\left(5.8 \times 10^{-4} \mathrm{~mol} \cdot \mathrm{L}^{-1}\right)$ in ethanol/water $(1$ : $5, \mathrm{v} / \mathrm{v})(\mathrm{a}), \mathrm{EAN}(\mathrm{b})$ and $\left[\mathrm{Bmim} \mathrm{PF}_{6}\right.$ (c) with inset photos for Tyndall effect indentification.

Figure S2. Geometries of Tery-MEE@Eu molecule based method with B3LYP/6-31G(d,p) basis sets. The gray, blue, white, red, and green balls represent carbon, nitrogen, hydrogen, oxygen and europium ions, respectively.

Figure S3. EDX spectrum for Tery-MEE@Eu $\left(5.8 \times 10^{-4} \mathrm{~mol} \cdot \mathrm{L}^{-1}\right)$ in ethanol/water $(1: 5, \mathrm{v} / \mathrm{v})$.

Figure S4. Snapshots of simulated boxes (a) and enlarged drawing of the H-bonds between hydrogen atom on $[\mathrm{Bmim}]^{+}$and oxygen atom on MEE segment (b). The gray, blue, white and red balls represent carbon, nitrogen, hydrogen and oxygen atoms, respectively.

Figure S5. Visual appearance of Tery-MEE@Eu under UV light $\left(\lambda_{\max }=365 \mathrm{~nm}\right)$ in ethanol/water (a), EAN (b) and $[\mathrm{Bmim}] \mathrm{PF}_{6}(\mathrm{c})$.

Figure S6. Luminescence decay curves of Tery-MEE@Eu samples in EAN before and after stabilization for one week under excitation at $330 \mathrm{~nm}$ and observed at $616 \mathrm{~nm}$ at room temperature.

Table S1. Characteristic luminescence parameters for Tery-MEE@Eu in EAN before and after stabilization for one week 


\section{DLS curves of Tery-MEE@Eu in different solutions}
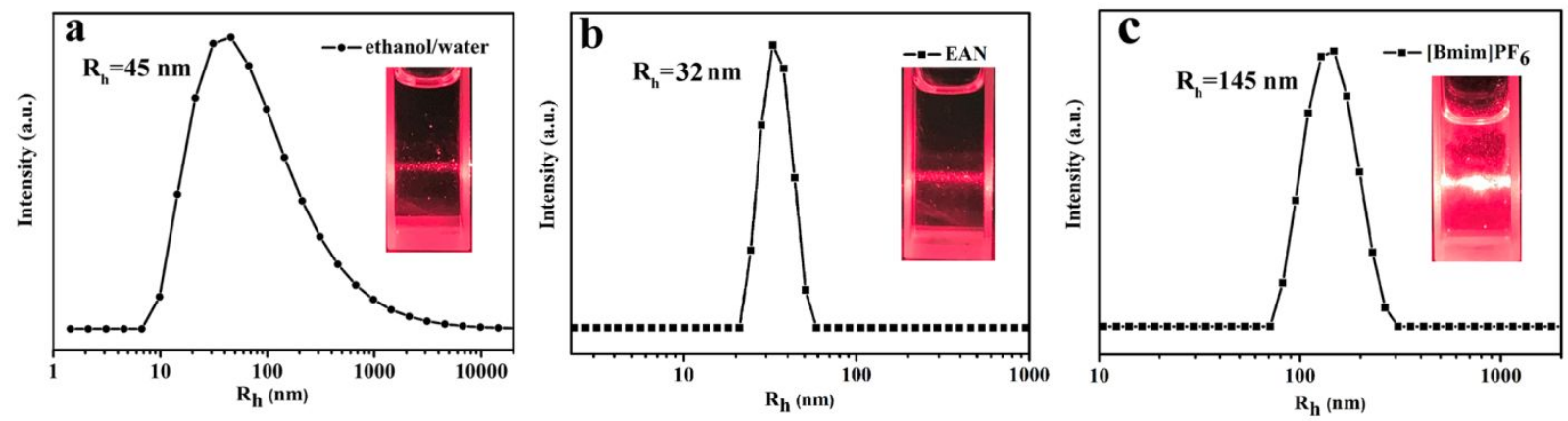

Figure S1. Size distribution of the aggregates formed by Tery-MEE@Eu $\left(5.8 \times 10^{-4} \mathrm{~mol} \cdot \mathrm{L}^{-1}\right)$ in ethanol/water (1: 5, v/v) (a), EAN (b) and [Bmim] $\mathrm{PF}_{6}(\mathrm{c})$ with inset photos for Tyndall effect indentification.

\section{Tery-MEE@Eu complex molecular length}

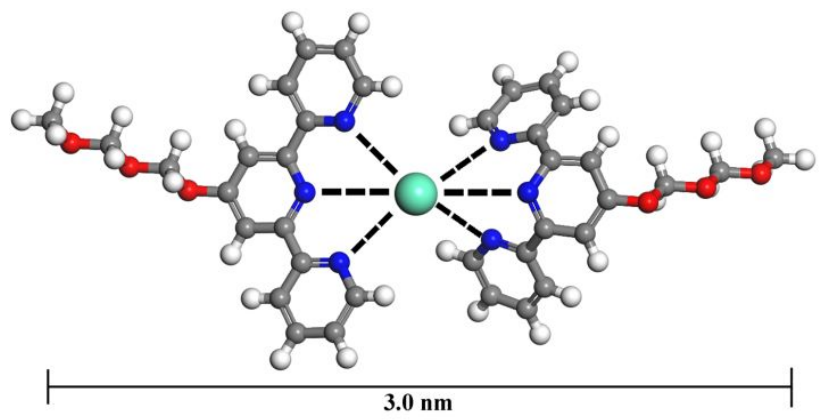

Figure S2. Geometries of Tery-MEE@Eu molecule based method with B3LYP/6-31G(d,p) basis sets. The gray, blue, white, red, and green balls represent carbon, nitrogen, hydrogen, oxygen and europium ions, respectively. 


\section{EDX spectrum for Tery-MEE@Eu aggregate}

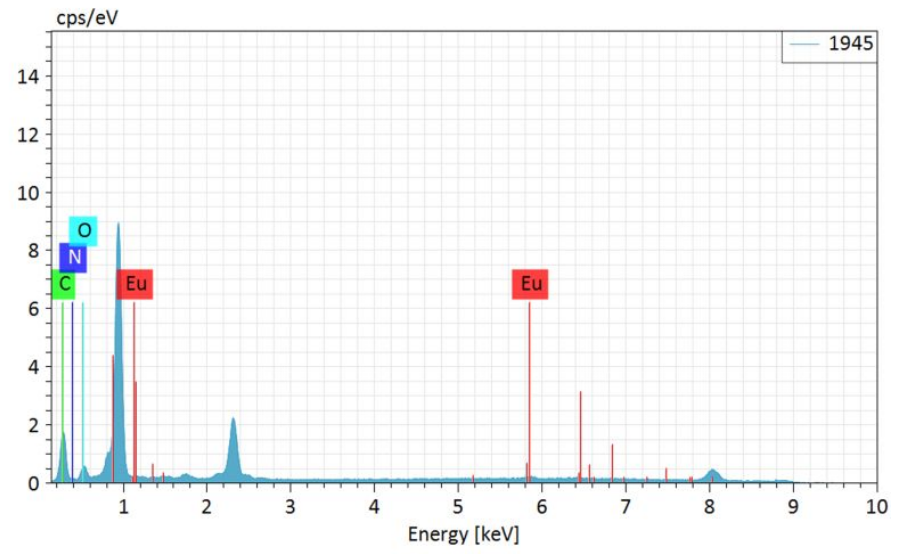

Figure S3. EDX spectrum for Tery-MEE@Eu $\left(5.8 \times 10^{-4} \mathrm{~mol} \cdot \mathrm{L}^{-1}\right)$ in ethanol/water $(1: 5, \mathrm{v} / \mathrm{v})$.

\section{Modeling of Tery-MEE bilayers in $\left[\mathrm{Bmim}^{\mathrm{P}} \mathrm{PF}_{6}\right.$}

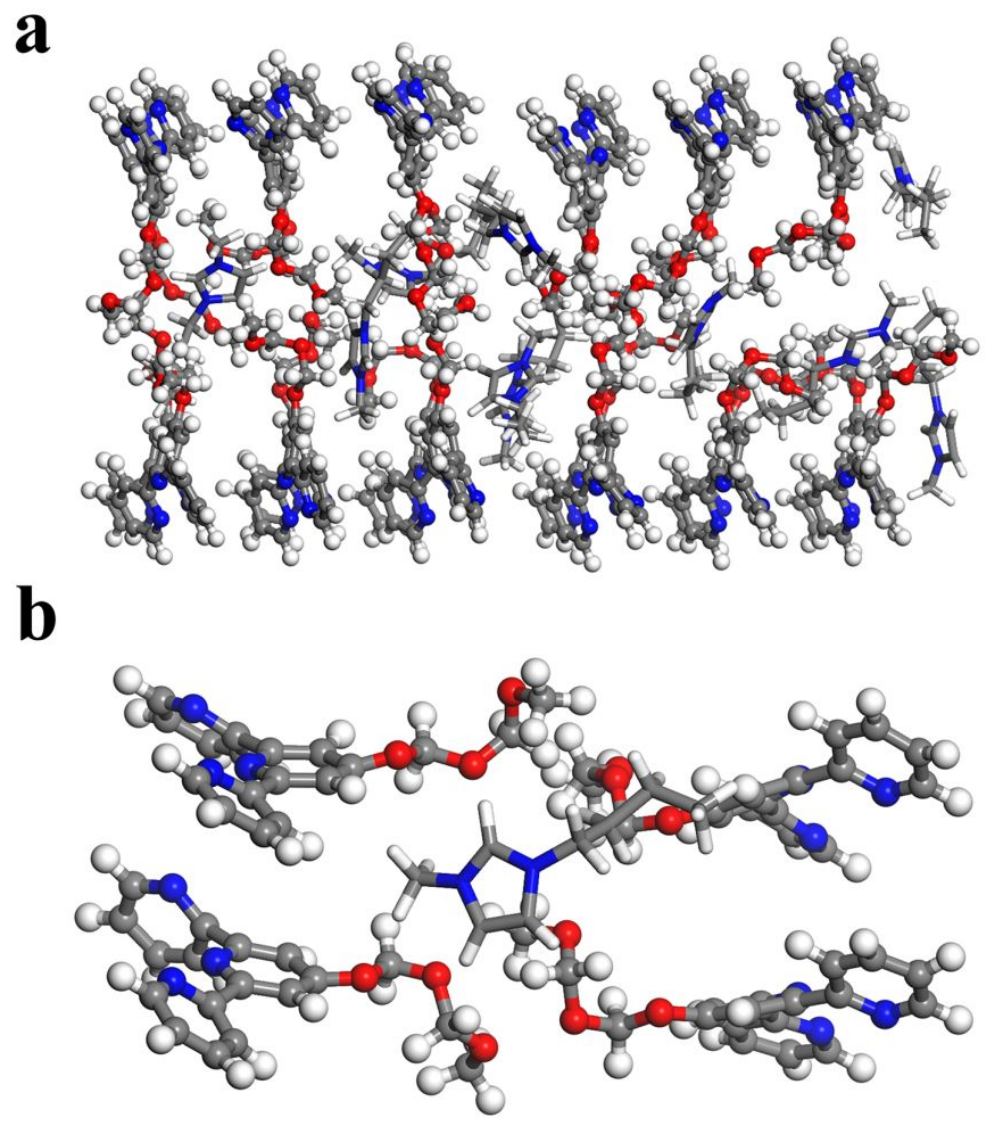

Figure S4. Snapshots of simulated boxes (a) and enlarged drawing of the H-bonds between hydrogen atom on $[\mathrm{Bmim}]^{+}$and oxygen atom on MEE segment (b). The gray, blue, white and red balls represent carbon, nitrogen, hydrogen and oxygen atoms, respectively. 


\section{Photograph of Tery-MEE@Eu in different solvents}

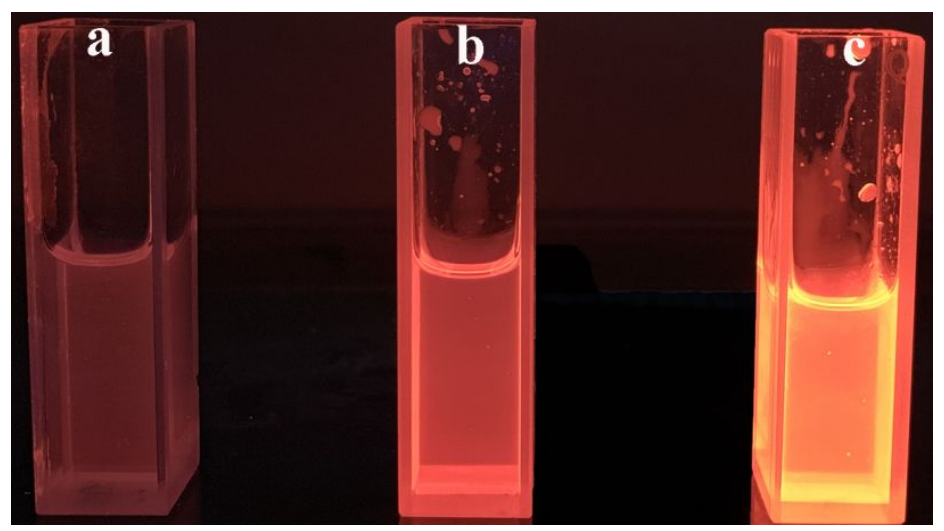

Figure S5. Visual appearance of Tery-MEE@Eu under UV light $\left(\lambda_{\max }=365 \mathrm{~nm}\right)$ in ethanol/water (a), EAN (b) and [Bmim] $\mathrm{PF}_{6}$ (c).

\section{The luminescence decay curves and Characteristic luminescence parameters}

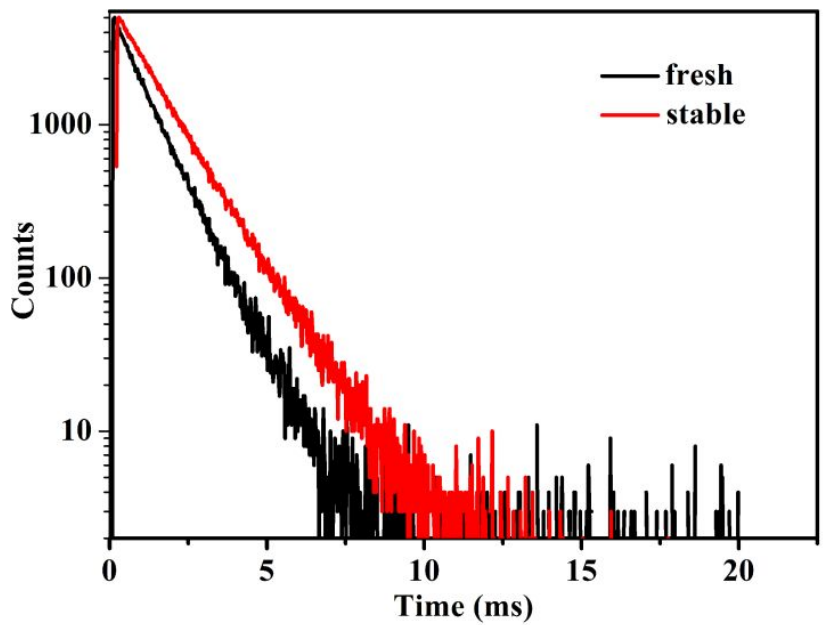

Figure S6. Luminescence decay curves of Tery-MEE@Eu samples in EAN before and after stabilization for one week under excitation at $330 \mathrm{~nm}$ and observed at $616 \mathrm{~nm}$ at room temperature. 
Table S1. Characteristic luminescence parameters for Tery-MEE@Eu in EAN before and after stabilization for one week

\begin{tabular}{cccccc}
\hline Sample & $K$ & $\tau(\mathrm{ms})$ & $\mathrm{Q}(\%)$ & $k_{\mathrm{r}\left(\mathrm{ms}^{-1}\right)}$ & $k_{\mathrm{nr}}\left(\mathrm{ms}^{-1}\right)$ \\
\hline fresh & 2.46 & 0.759 & 14.02 & 0.184 & 1.13 \\
stable & 4.51 & 0.998 & 18.67 & 0.188 & 0.816 \\
\hline
\end{tabular}

\section{Calculation of the radiative $\left(k_{\mathrm{r}}\right)$ or nonradiative $\left(k_{\mathrm{nr}}\right)$ rate constants and internal quantum efficiency $\left(Q_{\text {in }}\right)$}

Because of its stable intensity, the ${ }^{5} \mathrm{D}_{0} \rightarrow{ }^{7} \mathrm{~F}_{1}$ transition can be taken as a reference for the calculation of internal quantum efficiency $\left(Q_{\text {in }}\right)$. On the basis of intensity parameters obtained from the emission spectra, the total radiative rate of ${ }^{5} \mathrm{D}_{0}$ can be given by eq. (1),

$$
k_{r}=\sum_{J=0}^{4} k_{0 \rightarrow J}=k_{01} \sum_{J=0}^{4}\left(\frac{S_{0 J}}{S_{01}}\right)\left(\frac{v_{01}}{v_{0 J}}\right)
$$

where $S_{0 J}$ and $v_{0 J}$ were the integrated intensities and energy barycentres of ${ }^{5} \mathrm{D}_{0} \rightarrow{ }^{7} \mathrm{~F}_{J}(J=0 \sim 4)$ transitions in the emission curves, respectively. ${ }^{[1,2]} k_{01}$ was the Einstein coefficient of spontaneous emission for ${ }^{5} \mathrm{D}_{0} \rightarrow{ }^{7} \mathrm{~F}_{1}$ transition and could be determined as $\sim 50 \mathrm{~s}^{-1}$ in air for solid samples. ${ }^{[3]}$

Based on the fitted lifetimes $(\tau)$, the total decay rate of ${ }^{5} \mathrm{D}_{0}\left(k_{\mathrm{tot}}\right)$ could be calculated by eq. (2).[1,2]

$$
k_{\mathrm{tot}}=\frac{1}{\tau}=k_{r}+k_{n r}
$$

Assuming that only nonradiative and radiative decay processes were involved in the depopulation of ${ }^{5} \mathrm{D}_{0}$ state, the internal emission quantum efficiency $\left(Q_{\text {in }}\right)$ could be determined using the eq. (3).

$$
Q=\frac{k_{r}}{k_{r}+k_{n r}}
$$

\section{References}

(1) Shao, Y. F.; Yan, B.; Li, Q. P. Magnetic mesoporous silica nanosphere supported europium(III) tetrakis( $\beta$-diketonate) complexes with ionic liquid compounds as linkers. Eur. J. Inorg. Chem. 2013, 3, 381-387. 
(2) Yin, S. Y.; Sun, H.; Yan, Y.; Li, W.; Wu, L. X. Hydrogen-bonding-induced supramolecular liquid crystals and luminescent properties of europium-substituted polyoxometalate hybrids. J. Phys. Chem. B 2009, 113, 2355-2364.

(3) Hazenkamp, M. F.; Blasse, G. Rare-earth ions adsorbed onto porous glass: luminescence as a characterizing tool. Chem. Mater. 1990, 2, 2105-110. 